\title{
Comparison between Ultrasound-Guided Bilateral Ilioinguinal-Iliohypogastric Nerve Block and Ultrasound-Guided Transverses Abdominus Plane Block with the Usage Bubivacaine and Dexamethasone for Post-Cesarean Section Analgesia: A Pilot Study
}

\author{
REHAM MAHROUS, M.D. ${ }^{\mathbf{1}} \mathbf{2}^{\mathbf{2}}$; MAHMOUD ALALFY, Ph.D. ${ }^{\mathbf{3}},{ }^{\mathbf{4}}$; RABAB SABRY, M.D. ${ }^{\mathbf{1}}$; \\ NIHAL M. EL-DEMIRY, M.D. ${ }^{5}$; MANAL MOUSSA, M.D. ${ }^{5}$ and OMNIA MANDOUR, M.D. ${ }^{1}$ \\ The Department of Anesthesia, Surgical ICU and Pain Management, Cairo University ', Anesthesia, Aljazeerah Hospital ${ }^{2}$, \\ Reproductive Health \& Family Planning Department, National Research Centre ${ }^{3}$, Dokki, P.O:12622, Egypt. Affiliation ID: \\ 60014618, OB/Gyn, Aljazeerah Hospital ${ }^{4}$ and Obstetrics \& Gynecological Diseases Department, Cairo University ${ }^{\text {, Egypt }}$
}

\begin{abstract}
Background: Post-operative pain management following cesarean section (CS) can be done using abdominal field blocks like ilioinguinal-iliohypogastric (IL-IH) nerve block and transversus abdominis plane (TAP) block. The use of adjuvants such as dexamethasone can improve the sensory block's analgesic efficacy.
\end{abstract}

Aim of Study: This study aimed from this pilot study to compare ilioinguinal-iliohypogastric nerve block and transversus abdominus plane block regarding post-CS pain relief.

Patients and Methods: Twenty parturients undergoing CS were randomized to receive ultrasound-guided bilateral either IL-IH nerve block or TAP block. For both blocks, we used $20 \mathrm{ml}$ of $0.25 \%$ bupivacaine $+8 \mathrm{mg}$ dexamethasone for each side at the end of the operation. Patients' pain intensity was recorded at $0,4,8,12,24$ hours postoperatively using the visual analog scale (VAS). The total amount of nalbuphine consumed over the following 24 hours was recorded.

Results: Throughout the first 24 hours, the II-IH nerves block group had decreased pain scores (Visual Analog Score). In addition, the IL-IH group showed considerably less Nalbuphine consumption.

Conclusion: IL-IH nerve block provides more effective post-CS analgesia than TAP block.

Key Words: Cesarean section analgesia - Bubivacaine Dexamethasone.

\section{Introduction}

ADEQUATE postoperative pain management following cesarean section (CS) is important for parturients to ensure that they can take care of

Correspondence to: Dr. Reham Mahrous, E-Mail: dr memoo2003@hotmail.com their newborn and allow for early ambulation with less duration of hospital stay $[\mathbf{1 , 2}]$.

Several methods of postoperative pain control can be used like the intravenous injection of Nonsteroidal anti-inflammatory drugs (NSAIDs) and narcotics, epidural analgesia, and peripheral nerve blocks [3]. Narcotics are commonly associated with adverse effects such as pruritus, nausea, vomiting, drowsiness, and respiratory depression [4].

Abdominal field blocks, such as the ilioinguinaliliohypogastric (IL-IH) nerve block and the transversus abdominis plane (TAP) block, are wellknown and simple ways to give long-lasting pain relief and limit narcotic usage after surgery [5].

The ilioinguinal and iliohypogastric nerves are $\mathrm{T} 12$ and $\mathrm{L} 1$ branches that supply the inguinal region and run between the internal oblique and transversus abdominis muscles, slightly above the anterior superior iliac spine [6]. On the other hand, the neural afferents of the anterior rami of the spinal nerves T7-L1, which innervate the anterolateral abdominal wall, are targeted by TAP block

Adjuvants such as opioids, magnesium, dexmedetomidine, and dexamethasone were found to improve analgesic efficacy and extend the duration of the sensory block when added to local anesthetics

Aim of the work: This study is to assess the efficacy of II-IH nerve block and TAP block for 
post-cesarean section pain management utilizing dexamethasone as an adjuvant to bupivacaine under ultrasound guidance.

\section{Patients and Methods}

This pilot study was a randomized controlled trial that ran from April 2021 to May 2021 at Al Jazeera Hospital. 20 people were found to be eligible and recruited. They were split into two groups (Group T: TAP block group and Group I: Ilio-hypogastric and ilioinguinal nerves block group). The parturients were divided into two groups at random using an online random number generator, and concealing was done using serially numbered, opaque, and sealed envelopes.

After the study was approved by the institution's Ethics Review Committee, all participants gave a written informed consent to participate.

The population enrolled were ASA II parturients between the ages of 18 and 45 who were planned for an elective cesarean delivery. Exclusion criteria were hypertensive disorders, weight $<50 \mathrm{~kg}$ or $>100$, allergy to local anesthetics, and progressive neurologic disease.

Our primary outcome was pain severity, which was measured by the visual analog scale (VAS). The total amount of nalbuphine used as rescue analgesia in the first 24 hours was the secondary outcome.

All patients in our study received spinal anesthesia. After arrival to the operating room, an electrocardiogram (ECG), noninvasive blood pressure (BP), and pulse oximeter were applied. 18G cannula was inserted, and crystalloid infusion was started. Under strict aseptic technique, the subarachnoid block was performed using a $25 \mathrm{G}$ standard spinal needle, with the patient in a sitting position through the midline approach using $2 \mathrm{ml}$ (10mg) plain bupivacaine \& $25 \mathrm{mcg}$ Fentanyl.

The skin incision was allowed after confirming that the sensory block reached T6.

Patients' hemodynamics in form of BP, oxygen saturation, and heart rate were observed. Five milligrams of ephedrine were given intravenously if the mean arterial pressure fell below $65 \mathrm{mmHg}$.

Following skin closure and the application of chlorhexidine over needle puncture sites, either IIIH or TAP nerve blocks were conducted under strict aseptic conditions, depending on which intervention was elected. All blocks were performed by the same anesthesiologist using a high-frequency linear ultrasound probe (HFL 38) resonating at 12
$\mathrm{MHz}$ in the multi-beam mode (MicroMaxx; SonoSite, Bothell, WA, USA).

The ultrasound probe was inserted medial to the lateral one-third of a line connecting the anterior superior iliac spine (ASIS) and the umbilicus in the IL-IH nerves block group. Between the internal oblique and transverses abdominis muscles, the IL-IH nerves were detected. After negative aspiration, a syringe containing $20 \mathrm{ml}$ of 0.25 percent bupivacaine $+8 \mathrm{mg}$ dexamethasone was injected around the IL-IH nerve with a 22-gauge Quincke spinal needle. On the other side, an identical technique was followed.

For the TAP block, the three abdominal muscle layers were visualized by placing the ultrasound probe perpendicular to the midaxillary line between the iliac crest and the subcostal border. Between the internal oblique and the transversus abdominis muscle, the transversus abdominis plane was found. After negative aspiration, a 22-gauge Quincke spinal needle was used to inject a syringe containing $20 \mathrm{ml}$ of 0.25 percent bupivacaine $+8 \mathrm{mg}$ dexamethasone. On the other side, an identical process was followed.

Patients' pain intensity was recorded at $0,4,8$, 12, 24 hours post-operative using the VAS. The first pain assessment, at hour 0 was at the end of the operation. The following assessment was after 4 hours to ensure spinal regression below the level of L2 for proper assessment of IL-IH or TAP blocks. Patients were advised to request rescue analgesia when needed. Rescue analgesia supplied was in the form of $5 \mathrm{mg}$ nalbuphine. The Total nalbuphine consumption during 24 hours in milligrams was recorded. Any side effects were to be reported by the patients.

\section{Results}

Both groups had comparable mean ages, which was 30.8 with a standard deviation(SD) of 4.1 in the TAP block group (Group T and 32.4 with a SD of 4.3 in the Iliohypogastric and ilioinguinal blocks group (Group I). The $p$-value was 0.421 . The parity had no statistically significant difference between both groups. The mean and SD of parity was 2.3,1.4 in the TAP block group and 1.8,0.8 in the Iliohypogastric and ilioinguinal blocks group. (Table 1).

Table (1): Demographic data.

\begin{tabular}{llll}
\hline & Group T & Group I & $p$-value \\
\hline Age & $30.8(4.1)$ & $32.4(4.3)$ & $0.412^{*}$ \\
Parity & $2.3(1.4)$ & $1.8(0.8)$ & $0.325^{*}$ \\
\hline
\end{tabular}

Data are expressed as mean (SD). *Donates statistical significance. 
The Visual analog score (VAS) was 0 for both groups at the end of the operation (VAS 0) due to the effect of the spinal anesthesia. Throughout the first 24 hours, the Ilio-inguinal and Ilio-hypogastric nerves block group showed a lower VAS score than the TAP block group. This difference was statistically significant in all measurements. (Table 2, Fig. 1) The total Nalufin consumption was significantly lower in Group I. (Table 2).

Table (2): Visual Analog Score(VAS) and total Nalufin consumption in both groups.

\begin{tabular}{lccc}
\hline & Group T & Group I & $p$-value \\
\hline VAS 0 & 0 & 0 & \\
VAS 4 & $3.74(1.37)$ & $2.16(0.66)$ & $* 0.006$ \\
VAS 8 & $3.04(1.46)$ & $1.51(0.66)$ & $* 0.015$ \\
VAS 12 & $2.69(1.69)$ & $1.26(0.6)$ & $* 0.037$ \\
VAS 24 & $3.43(1.36)$ & $1.79(0.79)$ & $* 0.006$ \\
& & & \\
Total Nabuphine & $10.56(3.9)$ & $3.89(4.17)$ & $* 0.003$ \\
consumption (mg) & & & \\
\hline
\end{tabular}

- Group T is the TAP block group and group I is the iliohypogastric ilioinguinal nerve block group. VAS 0 is the baseline score just after the surgery. $4,8,12$, and 24 refers to the number of hours after the surgery.

* Donates statistical significance.

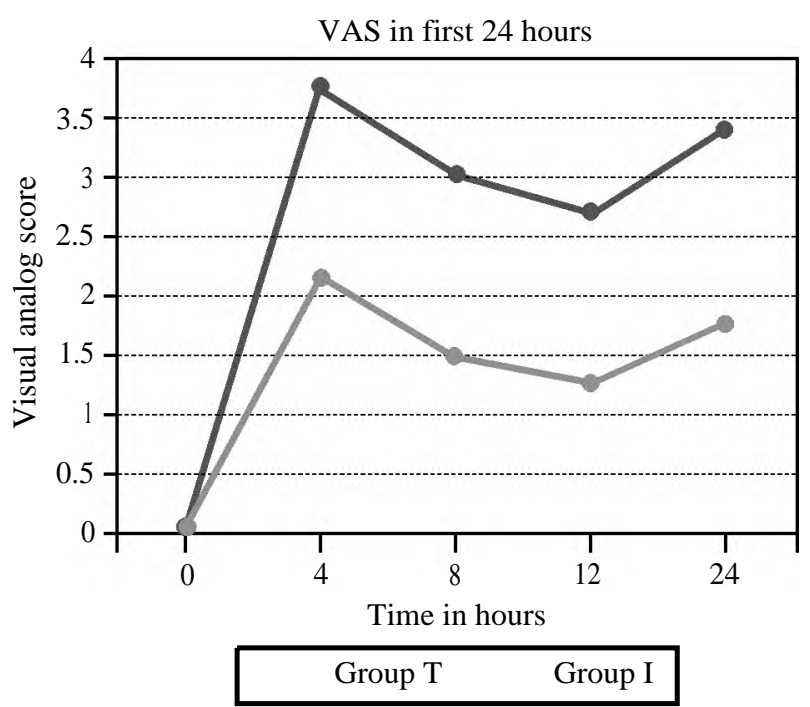

Fig. (2): VAS over the first 24 hours. Group T is the TAP block group and group I is the iliohypogastric ilioinguinal nerve block group.

\section{Discussion}

In terms of VAS, this study found a statistically significant difference between IL-IH nerve block and TAP nerve block. Throughout the first 24 hours, the IL-IH nerve block group had reduced pain scores. In addition, the IL-IH group consumed considerably less total nalbuphine. Both groups reported no negative effects from the blocks.
To our knowledge, no previous studies, comparing IL-IH nerve block to TAP block, utilized dexamethasone as a local anesthetic adjuvant in both blocks.

The improved analgesic efficacy of these regional techniques by adding dexamethasone to local anesthetic drugs was previously reported in the literature. In 2012, Amany S. Ammar et al., found that adding $8 \mathrm{mg}$ dexamethasone to bupivacaine in the TAP block resulted in a lower VAS score and a longer time to first analgesic request in a randomized controlled research. Also, there was lesser morphine consumption within 48 hours postoperatively in their 60 patients undergoing open abdominal hysterectomy [9]

Nurçin Gülhas et al., included 60 adult patients who needed abdominal hysterectomy that were randomly assigned to get TAP block with $19 \mathrm{~mL}$ bupivacaine hydrochloride 0.25 percent $+1 \mathrm{~mL}$ saline 0.9 percent or $19 \mathrm{~mL}$ bupivacaine hydrochloride 0.25 percent $+1 \mathrm{~mL}$ dexamethasone $(4 \mathrm{mg})$. The results showed that TAP block had higher analgesic efficacy, as determined by VAS, time to first analgesic, and total morphine consumption on adding dexamethasone [10]

Similarly, a study on 50 adult male patients who had inguinal hernia repair under general anesthesia. They received either $20 \mathrm{~mL}$ bupivacaine 0.5 percent plus $2 \mathrm{~mL}$ saline 0.9 percent or $20 \mathrm{~mL}$ bupivacaine 0.5 percent $+2 \mathrm{~mL}$ dexamethasone in an ultrasound-guided TAP block (8mg). The dexamethasone group had a lower total nalbuphine consumption in the first postoperative 24 hours and a better pain score at all time intervals of 4 , $8,12,16$, and 20 hours following surgery, according to Fouad et al's study [11].

Abdel-Wahab et al., examined the analgesic efficacy of two different dosages of dexamethasone added to bupivacaine in TAP block in 90 adult patients scheduled for unilateral open inguinal hernia repair under spinal anesthesia in another investigation. Under ultrasound guidance, $1 \mathrm{mg} / \mathrm{kg}$ bupivacaine 0.5 percent was coupled with either $4 \mathrm{mg}$ dexamethasone or $8 \mathrm{mg}$ dexamethasone to create a TAP block. In terms of the time of the first analgesic request and the VAS within the first 24 hours after surgery, the data showed no statistically significant difference between the two groups [12]

Hamid Kayalha et al., on the other hand, conducted a study in 2019 on 50 patients who underwent inguinal hernia repair under spinal anesthesia after being randomly assigned to one of two groups 
to receive IL-IH nerve block via direct injection of local anesthetics around nerves by the surgeon at the end of the operation. The control group received $2 \mathrm{ml} 0.5$ percent bupivacaine $+1 \mathrm{ml}$ normal saline, while the dexamethasone group received $2 \mathrm{ml} 0.5$ percent bupivacaine $+1 \mathrm{ml}$ dexamethasone (4mg). The addition of $4 \mathrm{mg}$ dexamethasone to bupivacaine in an IL-IH block generated a slight analgesic effect 12 hours after the surgery but did not extend the time to the first analgesic requirement, according to the study [13]

In terms of pain evaluation, our findings were consistent with those of Fredrickson MJ et al., who conducted a randomized controlled trial in New Zealand and found that the IL-IH nerve block considerably lowered pain scores after inguinal surgery in 41 pediatric patients [6]

Another study by Faiz et al., compared ultrasound-guided IL-IH nerve block to TAP block for analgesia following open inguinal hernia surgery in 90 adult patients. Postoperative pain assessment using a numerical rating scale (NRS) revealed that the IL-IH nerve block had a stronger analgesic effect than the TAP nerve block, both at rest and during movement, with no difference in postoperative meperidine requirements between the two blocks [14].

With regards to post-operative opioid consumption, For the first time, we record total nalbuphine consumption in the first 24 hours after surgery. Nalbuphine was not used as rescue analgesia in any of the previous studies comparing IL-IH nerve block and TAP block. The most commonly used analgesics were either opioids like morphine, tramadol, or meperidine or simple analgesics like ketorolac or paracetamol.

Our findings are in line with those of Mohamed et al., who compared ultrasound-guided IL-IH nerve block versus ultrasound-guided TAP nerve block. Patients who underwent IL-IH block were less likely to request paracetamol for analgesia than those who received TAP block. In their study, 50 children had inguinal hernia surgery under general anesthesia [15].

Additionally, an observational study led by Ahemed S.A. et al., found that in the 24 hours following surgery, the IL-IH group used significantly less total tramadol than the TAP block group for post-cesarean section pain management. The study included 102 women and found that, while there was no difference in post-operative pain scores between the two groups, the time to first analgesic request was longer in the IL-IH group than in the TAP group. We did not record the time of the first analgesic request in our trial [16].

S. Abiy et al., found no difference between the two blocks in terms of pain score assessment using the Numeric rating scale at $0,4,8,12$, and 24 hours post-operatively. The TAP block group, on the other hand, had reduced pain scores at 36 and 48 hours. The participants in this study were 72 pregnant women who were scheduled for elective CS. The landmark technique was employed in the prior two investigations, with investigators injecting $16 \mathrm{ml}$ of 0.25 percent bupivacaine into each side in the II-IH group and the same volume and concentration in the TAP block group as in our work [17].

JIN et al., observed that total morphine use was comparable in both groups after 12 hours, but dropped considerably in the IL-IH group at 24 and 48 hours following the surgery in a retrospective study of 124 females scheduled for CS. Both groups received the same amount of local anesthetic (Ropivacaine or Levobupivacaine) (20ml) [18]

In contrary to our findings, Bessmertnyj et al. in Russia found no statistically significant VAS difference between II-IH block and TAP block following caesarean delivery within the first 24 hours after delivery. On each side, $20 \mathrm{ml}$ of $0.25 \%$ ropivacaine was used as a local anaesthetic for the TAP block and $10 \mathrm{ml}$ of $0.5 \%$ for the IL-IH nerve block. A total of 164 parturients were enrolled in the trial, all of whom were given ultrasound-guided blocks [19].

Kiran et al., conducted a study to compare the efficacy of these two regional analgesic techniques for postoperative pain relief after CS and found no statistically significant differences in pain relief quality at all time intervals. They did find a statistically significant reduction in tramadol needs in the TAP block group when compared to the IL-IH group at all time intervals within the first 24 hours after surgery. The injected solution in the IL-IH group in Kiran et al.'s study was $10 \mathrm{ml}$ of 0.25 percent bupivacaine on each side. The difference between their and our results could be explained by the decreased volume of injected local anesthetic. For the TAP block group, they used the same quantity of 0.25 percent bupivacaine $(20 \mathrm{~mL})$ as we did in our study [20].

Aveline et al., on the other hand, compared ultrasound-guided transversus abdominis plane block to conventional II-IH nerve block in 273 
patients and found that TAP block was superior to IL-IH nerve block in terms of pain alleviation and postoperative morphine needs after inguinal hernia repair. Their results could be explained by their use of ultrasound rather than a blind approach for better nerve location [21].

Finally, we discovered that IL-IH nerve block is more effective than TAP nerve block in providing post-CS analgesia. The small number of cases in our study is the most significant drawback. As a result, we propose that this study be repeated with a larger number of patients to verify the findings.

\section{References}

1- BUHAGIAR L., et al.: "Predictors of post-caesarean section pain and analgesic consumption", J. Anaesthesiol. Clin. Pharmacol., Vol. 27, No. 2, p. 185, Apr. 2011.

2- JC E., PH P., R S., P L., R L. and TT H.: "Severity of acute pain after childbirth, but not type of delivery, predicts persistent pain and postpartum depression", Pain, Vol. 140, No. 1, pp. 87-94, Nov. 2008.

3- ROBERT W. HURLEY: "Acute Postoperative Pain," in Miller's Anesthesia, 7 th ed., Christopher L. Wu, Ed. Philadelphia, pp. 2757-2780, 2010.

4- LIM Y., LIM Y., JHA S., SIA A.T. and RAWAL N.: "Morphine for post-caesarean section analgesia: Intrathecal, epidural or intravenous?", Singapore Med. J., Vol. 46, No. 8, p. 392, 2005.

5- W M., et al.: "Bilateral ultrasound-guided transversus abdominis plane block combined with ilioinguinaliliohypogastric nerve block for cesarean delivery anesthesia", Anesth. Analg., Vol. 113, No. 1, pp. 134137, 2011.

6- MJ F., C P. and J H.: "Improved analgesia with the ilioinguinal block compared to the transversus abdominis plane block after pediatric inguinal surgery: A prospective randomized trial", Paediatr. Anaesth., Vol. 20, No. 11, pp. 1022-1027, Nov. 2010.

7- F B., J B. and C A.: "Transversus abdominis plane block: what is its role in postoperative analgesia?", Br. J. Anaesth., Vol. 103, No. 4, pp. 468-470, 2009.

8- M B., KR K., C K. and E A.: "The Analgesic Efficacy of Ultrasound-Guided Transversus Abdominis Plane Block in Adult Patients: A Meta-Analysis", Anesth. Analg., Vol. 121, No. 6, pp. 1640-1654, Dec. 2015.

9- AS A. and KM M.: "Effect of adding dexamethasone to bupivacaine on transversus abdominis plane block for abdominal hysterectomy: A prospective randomized controlled trial", Saudi J. Anaesth., Vol. 6, No. 3, pp. 229233, Jul. 2012.

10- NURÇIN GÜLHAS, GÜLAY KAYHAN, MUKADDER SANLI, ARZU KITLI, and MAHMUT DURMUS : "Effect of Adding Dexamethasone to Bupivacaine on Transversus Abdominis Plane Block [Transversus Abdominis Plane Blog a Eklenen Deksametazonun Etkisi]”, Med. Sci. , Vol. 4, No. 4, pp. 2732-2742, 2015.

11- FOUAD H.A., et al.: "Efficacy of preemptive dexamethasone added to bupivacaine in ultrasound guided transver- sus abdominus plain block for post-operative analgesia after inguinal herniorraphy", Vol. 4, No. 5, 2016.

12- ABDEL-WAHAB A.H., OSMAN E.A. and AHMED A.Y.: "Comparison of postoperative analgesic effects of two doses of dexamethasone in ultrasound-guided transversus abdominis plane block for inguinal hernia repair: A randomized controlled trial", Ain-Shams J. Anesthesiol., 131, Vol. 13, No. 1, pp. 1-8, Mar. 2021.

13- KAYALHA H., AHMADI GOORAJI S., PARSA H. and BEIGOM KHEZRI M.: "The Analgesic Efficacy of Low Dose Dexamethasone Added to Bupivacaine in Ilioinguinal and Iliohypogastric Nerves Block in Patients Undergoing Inguinal Hernia Surgery under Spinal Anesthesia", J. Adv. Med. Biomed. Res., Vol. 27, No. 124, pp. 16-22, Sep. 2019.

14- SHR F., ND N., S N., S D.-F., GG H. and P R.: "A clinical trial comparing ultrasound-guided ilioinguinal / iliohypogastric nerve block to transversus abdominis plane block for analgesia following open inguinal hernia repair," J. Pain Res., Vol. 12, pp. 201-207, 2019.

15- MOHAMED and KAMAL M.M.: "Comparison of postoperative analgesia of ultrasound-guided ilioinguinal/ iliohypogastric nerve block versus ultrasound-guided TAP block for pediatric inguinal hernia repair", Ain-Shams J. Anaesthesiol., Vol. 8, No. 4, p. 658, 2015.

16- AHEMED S.A., DENU Z.A., KASSAHUN H.G. and FENTIE D.Y.: "Efficacy of Bilateral Transversus Abdominis Plane and Ilioinguinal-Iliohypogastric Nerve Blocks for Postcaesarean Delivery Pain Relief under Spinal Anesthesia”, Anesthesiol. Res. Pract., Vol. 2018, 2018.

17- ABIY S., et al.: "Comparison of bilateral ilioinguinaliliohypogastric nerve block versus transverses abdominis nerve block for postoperative pain management for parturient undergoing elective cesarean section in Dilla University Referral Hospital, Ethiopia. A randomized controlled trial,” Int. J. Surg. Open, Vol. 26, pp. 22-29, Jan. 2020 .

18- Y J., Y L., S Z., G Z. and M Y.: "Comparison of ultrasoundguided iliohypogastric/ilioinguinal nerve block and transversus abdominis plane block for analgesia after cesarean section: A retrospective propensity match study", Exp. Ther. Med., Vol. 18, No. 1, May 2019.

19- BESSMERTNYJ A.E., ANTIPIN E.E., UVAROV D.N., SEDYH S.V. and NEDASHKOVSKY E.V.: "Comparison of the effectiveness of ilioinguinal-iliohypogastric blockade and transversus abdominis plane block for analgesia after cesarean section | Cochrane Library", Anesteziol. Reanimatol., Vol. 60, No. 2, pp. 51-54, 2015.

20- LV K., T S., VRH K., N K. and S P.: "Relative Efficacy of Ultrasound-guided Ilioinguinal-iliohypogastric Nerve Block versus Transverse Abdominis Plane Block for Postoperative Analgesia following Lower Segment Cesarean Section: A Prospective, Randomized Observerblinded Trial", Anesth. Essays Res., Vol. 11, No. 3, p. 713, 2017.

21- C A., et al.: "Comparison between ultrasound-guided transversus abdominis plane and conventional ilioinguinal/iliohypogastric nerve blocks for day-case open inguinal hernia repair", Br. J. Anaesth., Vol. 106, No. 3, pp. 380-386, 2011. 


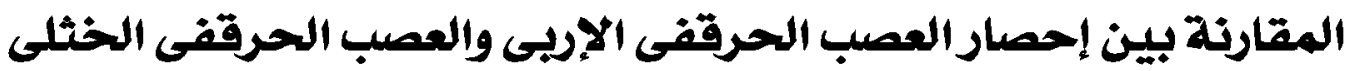

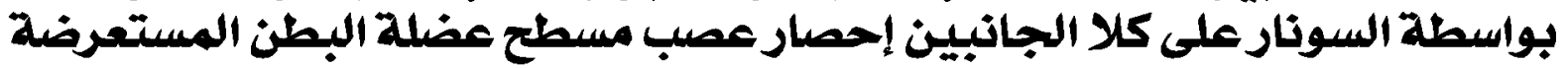

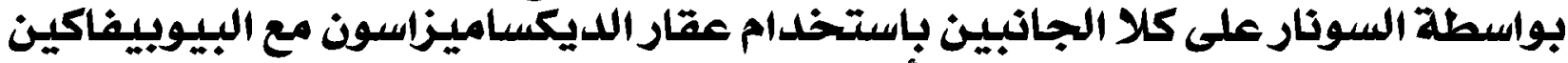

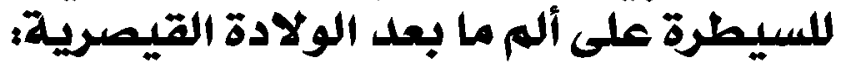

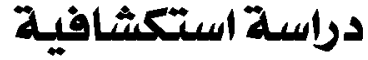

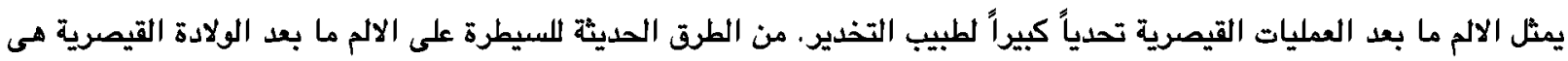
إحصار العصب الصرقفى الإربى والعصب الحرقفى الخثلى وإحصار مسطع عضلة البطن المستعرضة.

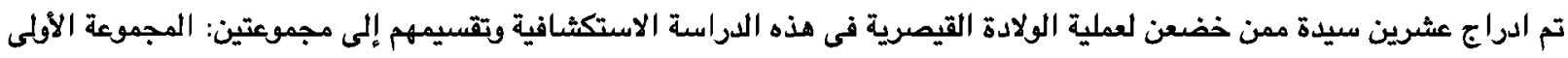

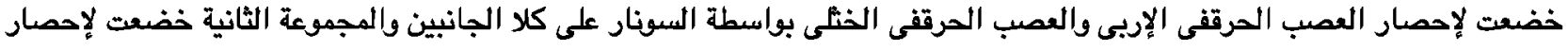

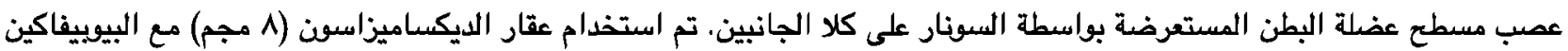

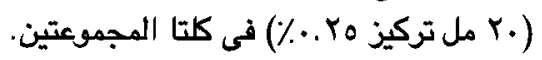

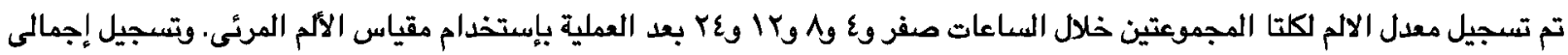
جرعات النالوفين المستخدمة في أفل عَل سعاعة.

أثثاء أقل عَ ساعة كانت معدلات الألم أقل إحصائياً في المجموعة التى خضعت لإحصار العصب الحرقفى الإربى والعصب الحرقفى الخثلى

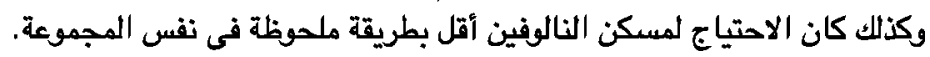

